\title{
Arborização Urbana na bacia do Rio Roncador em Duque de Caxias
}

Urban Afforestation in the Roncador River basin in Duque de Caxias

Reforestación urbana en la cuenca del río Roncador en Duque de Caxias

Thaís dos Santos Costa

Graduanda, UFRJ, Brasil

thais.costa@fau.ufrj.br

\section{Samantha Monteiro Silva}

Graduanda, UFRJ, Brasil.

samantha.silva@fau.ufrj.br

Jorge Nassar Fleury da Fonseca

Professor Doutor, UFRJ, Brasil.

jorgefleury@fau.ufrj.br 


\section{Revista Científica ANAP Brasil}

ISSN 1984-3240 - Volume 14, número 35, 2021

\section{RESUMO}

O inchaço populacional das regiões centrais das grandes cidades e a expansão para as áreas periféricas adjacentes, configurando aquilo que se entende por expansão urbana, apontam para a necessidade de um planejamento que equacione o aumento dos serviços e das infraestruturas urbanas e garantia de um ambiente urbano de qualidade para a população. Tornar as cidades e os assentamentos humanos inclusivos, seguros, resilientes e sustentáveis é um desafio para os gestores públicos e planejadores urbanos. Entendendo a importância da arborização urbana para a melhoria da qualidade de vida dos habitantes das cidades, e para a construção de cidades habitáveis e resilientes, o presente trabalho aborda a arborização em uma área de expansão na Bacia do Rio Roncador, no município de Duque de Caxias, na Região Metropolitana do Rio de Janeiro. A partir de dados climáticos e de estudos de tendências de expansão urbana sobre as áreas de cobertura vegetal existentes no município, foi desenvolvido um diagnóstico quantitativo de arborização (levantamento in loco e imagens do satélite Landsat 8). O mapeamento da arborização foi associado aos dados de climatologia desenvolvidos pelos laboratórios DCLURME (UFRRJ) e LASA (UFRJ) e analisados segundo o índice ideal de arborização. Os mapas foram elaborados com o software QGIS. Os resultados apontam para condições de arborização muito aquém dos parâmetros ideais contribuindo para um baixo índice de qualidade e habitabilidade na área analisada.

PALAVRAS-CHAVE: Arborização. Sustentabilidade Urbana. Duque de Caxias-RJ

\section{RESUME}

The population swelling in the central regions of large cities and the expansion to adjacent peripheral areas, configuring what is understood as urban expansion, point to the need of a planning that takes in account the increasing demand of urban services and infrastructures and the guarantee of environmental quality for urban population. Making cities and human settlements inclusive, safe, resilient and sustainable is a challenge for public managers and urban planners. Understanding the importance of urban afforestation for improving the quality of life of city dwellers, and for the construction of liveable and resilient cities, this paper addresses afforestation in an expansion area, in Roncador river bassin, of the municipality of Duque de Caxias, in the Metropolitan Region of Rio de Janeiro. Based on climatic data and studies of urban expansion trends on the existing vegetation covered areas in the municipality, a quantitative diagnosis of afforestation was developed (in loco survey and Landsat 8 satellite images). The afforestation mapping was associated with the climatology data developed by the DCLURME (UFRRJ) and LASA (UFRJ) laboratories and analyzed according to the ideal afforestation index. The maps were created with QGIS software. The results point to afforestation conditions far below the ideal parameters, contributing to a low level of quality and habitability in the analyzed area.

KEYWORDS: Afforestation. Urban Sustainability. Duque de Caxias -RJ

\section{RESUMEN}

El aumento de población en las regiones centrales de las grandes ciudades y la expansión a zonas periféricas cercanas, configurando lo que se entiende como expansión urbana, apuntan a la necesidad de una planificación que tenga en cuenta la creciente demanda de servicios e infraestructuras urbanas y la garantía de la calidad ambiental para la población urbana. Hacer que las ciudades y los asentamientos humanos sean inclusivos, seguros, resilientes y sostenibles es un desafío para los administradores públicos y los planificadores urbanos. Entendiendo la importancia de la forestación urbana para mejorar la calidad de vida de los habitantes de la ciudad y para la construcción de ciudades habitables y resilientes, este trabajo aborda la arborización en un área de expansión, en la cuenca del río Roncador, del municipio de Duque de Caxias, en el Región Metropolitana de Río de Janeiro. Con base en datos climáticos y estudios de tendencias de expansión urbana en las áreas cubiertas de vegetación existentes en el municipio, se desarrolló un diagnóstico cuantitativo de arborización (levantamiento in loco e imágenes satelitales Landsat 8). El mapeo de la arborización se asoció con los datos climatológicos desarrollados por los laboratorios DCLURME (UFRRJ) y LASA (UFRJ) y analizados según el índice ideal de forestación. Los mapas se crearon con el software QGIS. Los resultados apuntan a condiciones de arborización muy por debajo de los parámetros ideales, contribuyendo a un bajo nivel de calidad y habitabilidad en el área analizada.

PALABRAS CLAVE: Arborización, Sustentabilidad urbana, Duque de Caxias-RJ 


\section{Revista Científica ANAP Brasil}

ISSN 1984-3240 - Volume 14, número 35, 2021

\section{INTRODUÇÃO}

O crescimento populacional e a crescente demanda por espaços úteis para ocupação tem se mostrado cada vez uma preocupação no pensamento e na estruturação das áreas urbanas. As relações econômicas e a lógica de mercado induzem os habitantes à busca de locais de moradia cada vez mais próximos das áreas de trabalho, ocasionando um inchaço das regiões centrais das grandes cidades, onde se acumulam as principais oportunidades e demandas, e a expansão para as áreas periféricas adjacentes configurando aquilo que se entende por expansão urbana. O alastramento ou expansão urbana ocorre com crescimento do contingente populacional de uma região ou o aumento físico da área.

Segundo dados apresentados pela Organização das Nações Unidas - ONU em 2019, $55 \%$ da população mundial vivia em áreas urbanas e a expectativa é de que esta proporção aumente para $70 \%$ até 2050 . Tal sinalização aponta para a necessidade de planejamento que equacione aumento dos serviços e das infraestruturas urbanas e garantia de um ambiente urbano de qualidade para a população, prevendo os impactos e criando estratégias para a minimização de danos à saúde e ao ambiente, visando a sustentabilidade. Ainda em 2015, representantes dos 193 Estados-membros da ONU se reuniram e reconheceram que a erradicação da pobreza em todas as suas formas e dimensões, incluindo a pobreza extrema, é o maior desafio global e um requisito indispensável para o desenvolvimento sustentável. Foi então adotado o documento "Transformando o Nosso Mundo: A Agenda 2030 para o Desenvolvimento Sustentável” (A/70/L.1), através do qual os países comprometeram-se a tomar medidas ousadas e transformadoras para promover o desenvolvimento sustentável nos próximos 15 anos sem deixar ninguém para trás. Nesse documento foram definidos 17 objetivos, dentre os quais o objetivo 11 "Tornar as cidades e os assentamentos humanos inclusivos, seguros, resilientes e sustentáveis é um desafio para os gestores públicos e planejadores urbanos". No desdobramento desse objetivo surgem alguns pontos que possuem uma conexão direta com a arborização urbana: adaptação à mudança do clima; o acesso universal a espaços públicos seguros, inclusivos, acessíveis e verdes; preservação da qualidade do ar.

As questões de resiliência e sustentabilidade ainda estão pouco presentes na agenda de planejamento dos municípios da região metropolitana do Rio de Janeiro. Contudo, como assinala Costa (1999), ao discutir a noção de desenvolvimento urbano sustentável, diferentes autores enfatizam ainda a importância das áreas de fronteiras urbanas, de periferias, por serem pontos de encontro entre espaços construídos e não-construídos. O objeto deste trabalho é a arborização urbana em uma dessas periferias urbanas, que se colocam como áreas de expansão urbana, ainda com baixa densidade e potencialidade para uma ocupação urbana mais sustentável no município de Duque de Caxias na Região Metropolitana do Rio de Janeiro.

Os diferentes manuais que tratam da arborização urbana, definem três setores individualizados que estabelecem interfaces entre si: i) áreas verdes públicas, destinadas ao lazer, como praças e parques, que permitem o convívio direto com a natureza 2) áreas verdes privadas ou semiprivadas, (instituições públicas como colégios, campus universitários, clubes, hospitais, hotéis) compostas pelos remanescentes vegetais significativos nos lotes incorporados à malha urbana; e, 3) arborização de ruas e vias públicas. (BIONDI, 2000; MANEROLLI e MASCARÓ, 2010). 


\section{Revista Científica ANAP Brasil}

ISSN 1984-3240 - Volume 14, número 35, 2021

A vegetação é fundamental para: a manutenção do equilíbrio do ciclo hidrológico; para a retenção e estabilização dos solos; a infiltração da água, reduzindo as taxas do escoamento superficial e evitando a sobrecarga dos rios urbanos; a estabilidade de microclimas; a redução de insolação direta; a redução das velocidades dos ventos; e a ampliação das taxas de evapotranspiração, melhorando a qualidade ambiental nas cidades e contribuindo para o bemestar (BITTAR, 2018; MELLO, 2020; MILANO; DALCIN, 2000).

Em relação ao clima, as árvores auxiliam no conforto térmico à umidade do ar. Sob grupamentos arbóreos, a temperatura é de 3 a 4 graus menor que nas áreas expostas à radiação solar (MASCARÓ e MASCARÓ, 2009). A sombra das árvores torna ambientes abertos em espaços públicos mais atraentes para a população por serem mais frescos, aspecto importante em áreas de clima quente como grande parte das cidades brasileiras. As árvores também ajudam na melhoria da qualidade do ar e na redução da poluição, absorvendo gás carbônico através da fotossíntese; elas também absorvem água, melhorando, assim, a infiltração da água no solo, diminuindo o risco de enchentes.

A presença de bons níveis de arborização em regiões metropolitanas proporciona melhorias relevantes relacionadas à outros aspectos como: uma estabilidade de microclimas devido à redução de amplitudes térmicas em áreas de grande densidade populacional; redução de insolação direta; redução das velocidades dos ventos e ampliação das taxas de evapotranspiração, melhorando a qualidade ambiental nas cidades e contribuindo para o bemestar.(BITTAR, 2018; MELLO,2020; MILANO 2000)

Existem ainda segundo Herzog, outros benefícios da presença das árvores, menos evidentes e contabilizáveis, como o fato de cada uma delas: abrigar uma imensidão de espécies que dela dependem para viver, como bromélias, orquídeas, insetos, pássaros, etc. Desse modo, segundo a autora, a arborização urbana deve ser prioritária para cidades sustentáveis (HERZOG, 2013).

O investimento na melhoria e ampliação das áreas verdes urbanas contribuem de forma significativa para as condições de habitabilidade de uma região: É possível observar melhorias nos indicadores de saúde da população e de aumento de produtividade - resultado da melhoria nos quesitos de saúde mental. Cidades que promovem espaços verdes de qualidade estão investindo diretamente na redução de custos com saúde.

\section{OBJETIVOS}

Entendendo a importância da arborização urbana para a melhoria da qualidade de vida dos habitantes das cidades, e para a adaptação à mudança climática, possibilitando a redução das ilhas de calor e o aumento da permeabilidade do solo, o que contribui para reduzir a susceptibilidade à inundações, o presente trabalho aborda a arborização em nesta área de expansão do município de Duque de Caxias. Esse estudo é parte da pesquisa desenvolvida no Laboratório de Estudos de Águas Urbanas, que aborda questões socioambientais na Bacia do Rio Roncador, localizada em Imbariê, terceiro distrito de Duque de Caxias, município integrante da Baixada Fluminense. A pesquisa busca desenvolver um projeto de requalificação ambiental para a bacia, atentando-se para questões arquitetônicas e urbanísticas, abordando diversos aspectos, dentre eles, a arborização urbana. Nesse sentido, o presente estudo tem por objetivo principal quantificar e qualificar a cobertura verde arbórea existente em vias públicas na bacia do Rio Roncador em Duque de Caxias/RJ. 


\section{Revista Científica ANAP Brasil}

ISSN 1984-3240 - Volume 14, número 35, 2021

A Bacia do Rio Roncador (Figura 1), possui uma área de $17,32 \mathrm{~km}^{2}$, está inserida na Sub-bacia dos rios Estrela, Inhomirim e Saracuruna. Esta, por sua vez, cobre parcialmente os municípios de Duque de Caxias, Magé e Petrópolis, contando com uma área de quase $349 \mathrm{~km}^{2}$, sendo considerada uma das principais sub-bacias da Bacia da Baía de Guanabara. Tem como rio principal, o rio Roncador, que com 7,36 km de extensão, começa seu percurso nas proximidades da Avenida Automóvel Clube e passa a jusante pela Rodovia Rio-Magé (BR 116 - 493).

Figura 1 - Localização da área de estudo.

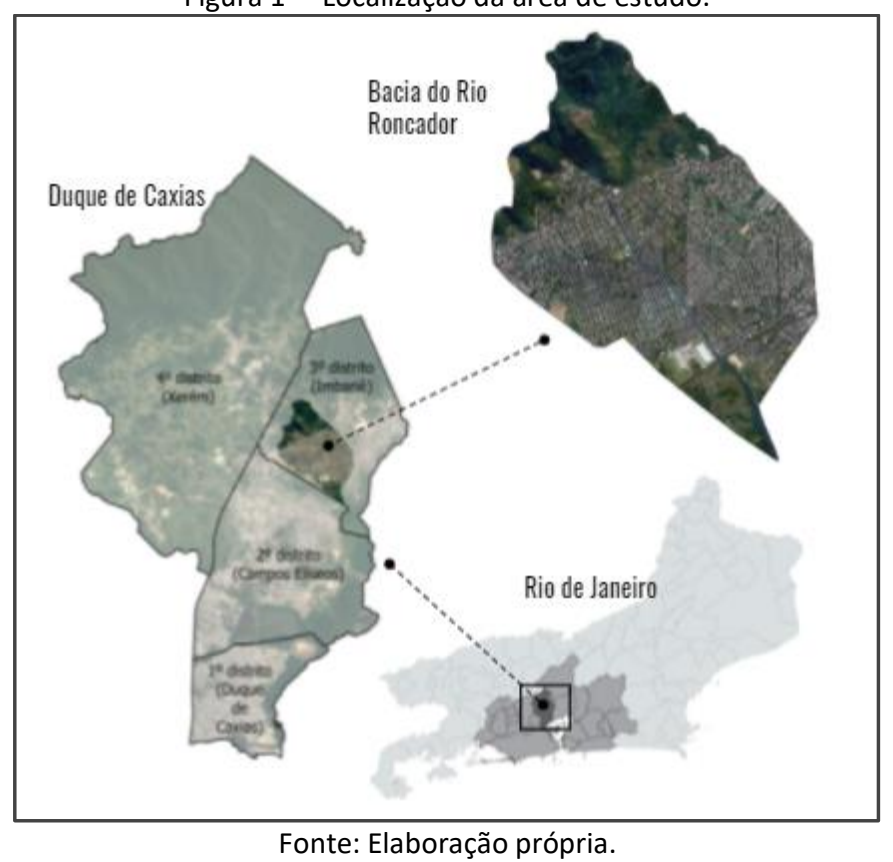

O município é dividido em quatro distritos: 1엄 distrito - Duque de Caxias, 2o distrito Campos Elíseos, 3 distrito - Imbariê e 4ㅇ distrito - Xerém. A Bacia do Rio Roncador se localiza integralmente no 3o distrito - Imbariê, abarcando principalmente os bairros Cidade Parque Paulista, Barro Branco e Jardim Anhangá, os quais serão enfatizados nas análises deste estudo.

O município apresentou constante expansão demográfica após a segunda metade do século 20. A presença das ferrovias e posteriormente da rodovia Washington Luiz atraíram indústrias como a antiga Fábrica Nacional de Motores (FNM), Refinaria Duque de Caxias (REDUC) entre outras, atraindo novos moradores e consequentemente a expansão da ocupação urbana. Na década de 2000, a população já era composta por 775.456 habitantes, no último censo demográfico do IBGE (2010) constatou-se que a população chegara a 855.048 habitantes.

De acordo com Neves et al. (2019), em Duque de Caxias, entre 2007 e 2016, foi possível perceber a expansão da malha urbana de forma expressiva sobre as áreas de vegetação rasteira, principalmente no 20 e 3 o distritos (Figura 2). Já o segundo tipo de cobertura que perdeu mais espaço para a urbanização foram as coberturas de vegetação densa. Além da supressão da vegetação decorrente do avanço da área urbana em Duque de Caxias, Neves et al. chamam atenção para uma tendência do direcionamento desta para locais de alta suscetibilidade à inundação, o que aumenta a preocupação em relação à segurança dos ocupantes, uma vez que a região é marcada pelos seus rios e eventos de inundação (BRITTO; QUINTSLR; PEREIRA, 2019). 
Figura 2 - Uso e cobertura da terra no município de Duque de Caxias.

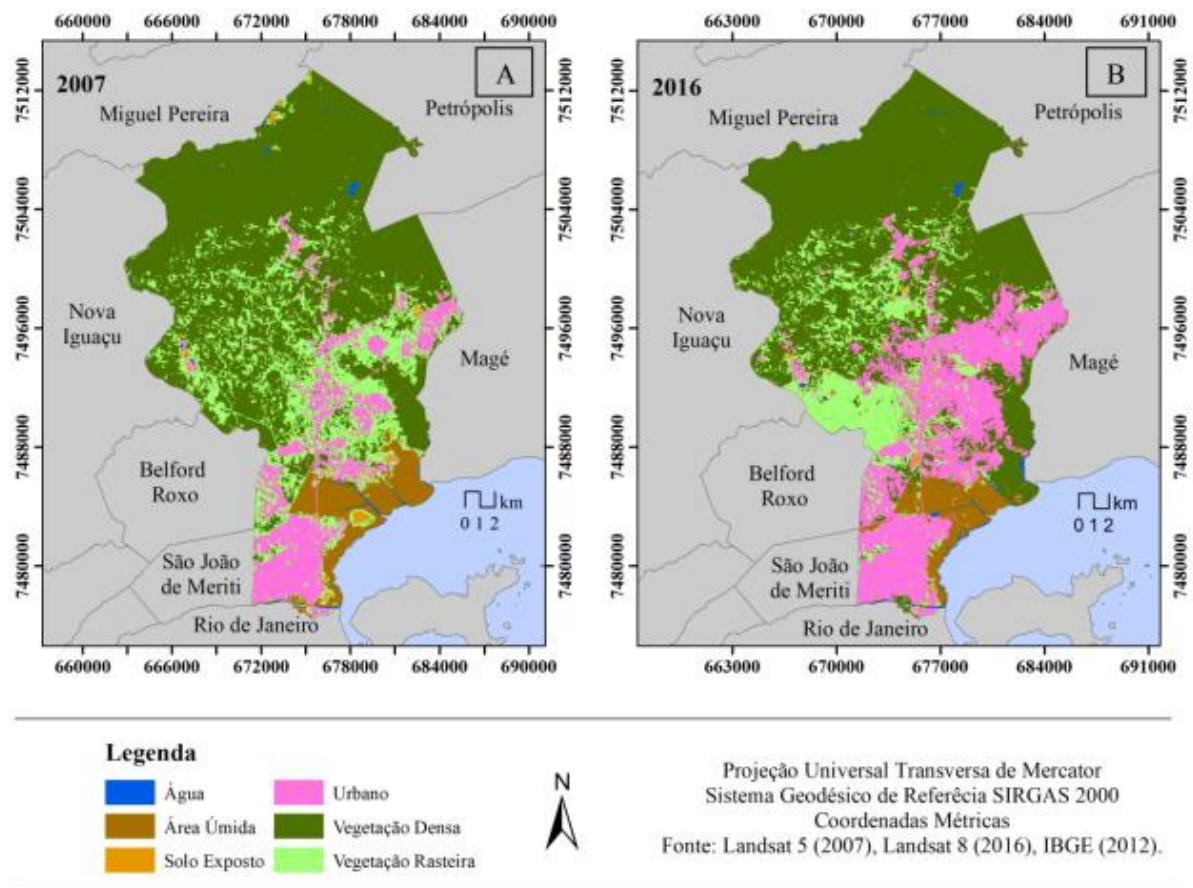

Fonte.Neves, L. et al. (2019, p.26)

Os mapas apresentados demonstram que primeiro e segundo distritos já apresentam urbanização consolidada, entretanto, o terceiro e quarto distritos estão em processo de expansão e ainda possuem espaços com possibilidade de serem planejados, evitando que a ocupação ocorra em locais de risco a impedindo a supressão das coberturas vegetais, construindo um plano para a construção de assentamentos urbanos seguros e resilientes.

\section{METODOLOGIA}

Para atender o objetivo principal de pesquisa foram traçados objetivos específicos, sendo eles: análise de temperatura de superfícies comparadas à ocupação do solo; levantamento de unidades arbóreas em vias públicas dentro do recorte da bacia; análise de suportes urbanísticos legais vigentes no recorte de estudo; determinação do índice arbóreo por quilômetro de rua percorrida e análise de viabilidade para implementação de um plano de arborização urbana para a bacia.

Para o estudo de arborização urbana na bacia, inicialmente foram analisados mapeamentos da base de climatologia desenvolvidos pelo Laboratório de Estudos da Dinâmica do Clima Urbano de Regiões Metropolitanas - DCLURME (Departamento de Geografia/UFRRJ) e o Laboratório de Análise de Satélites Ambientais - LASA (Departamento de Meteorologia/UFRJ), com informações geradas por sensoriamento remoto, da série Landsat 5, 7 e 8, que retratam a média anual da temperatura da superfície da cidade e região metropolitana do Rio de Janeiro. Foi realizado um recorte da região da bacia do Rio Roncador seguido de uma sobreposição de camadas para comparação dos registros de temperatura de superfície com os mapas de densidade demográfica. Tal mapeamento teve como objetivo ratificar a relação entre o microclima e a cobertura vegetal. A fim de validar tal análise, foi investigado o mesmo tipo de 


\section{Revista Científica ANAP Brasil}

ISSN 1984-3240 - Volume 14, número 35, 2021

estudo na região metropolitana do Rio de Janeiro e São Paulo e os mapas comprovaram a relação área verde com a temperatura de forma que as áreas com mais massas verdes apresentam temperaturas mais baixas que nas partes densamente urbanizadas.

A etapa seguinte do estudo foi o levantamento das condições de arborização nesse território. Para avaliar a situação da bacia do Rio Roncador foi feito um levantamento e mapeamento da arborização na bacia (Figura 3). O levantamento se realizou em parte in loco, mas após o início da pandemia, se deu através exclusivamente de imagens Landsat 8.

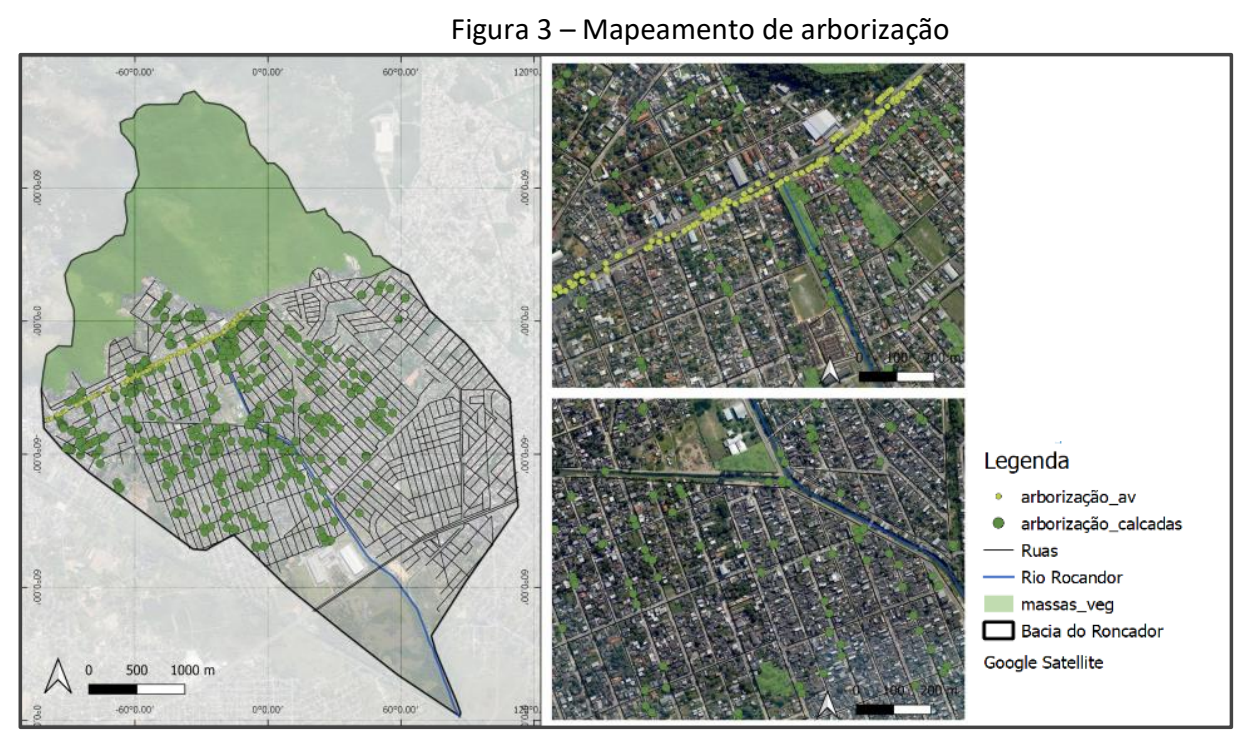

Fonte:Elaboração própria, 2020

Para estudo de arborização urbana e/ou áreas vegetadas existe uma diversidade de índices com metodologias que se utilizam dos mais variados elementos, não havendo possibilidade de comparação entre os mesmos. No presente estudo, optou-se por desconsiderar a vegetação do interior dos lotes, sendo contabilizadas apenas as presentes nas calçadas e territórios públicos; dessa forma, para análise de resultados optou-se pelo índice de indivíduos arbóreos por quilômetro de rua percorrido dentro do bairro de Silva Filho et al. (2002), sendo o que mais atende à quantificação proposta pelo trabalho. $O$ índice recomenda a existência de 200 árvores por km de rua.

O estabelecimento de diretrizes, buscando conciliar as árvores com os diversos usos do solo urbano, auxilia e norteia o planejamento da arborização (NESPOLO, et al.). Em nível federal não existe política nacional de arborização urbana que norteie os municípios e estados. A nível estadual e municipal, alguns municípios e estados inseriram questões relativas à arborização em seus Planos Diretores de Desenvolvimento Urbano ou elaboraram um Plano Diretor de Arborização Urbana à parte, como o município do Rio de Janeiro e o estado de São Paulo.

A falta de diretrizes estaduais e federais em relação a arborização urbana dificultam a elaboração e a padronização de planos ou manuais pelas prefeituras, que nem sempre conhecem os requisitos fundamentais para elaboração de um plano adequado que possa ser posto em prática. A instituição de planos de arborização urbana como instrumentos de regulamentação da expansão e ordenamento urbano, além de planejar novos plantios também 
garante a manutenção, controle e reparo de danos das espécies, favorecendo as políticas de planejamento e construção de cidades sustentáveis. Apesar de não ser obrigatória, a inserção do planejamento da arborização urbana nos instrumentos da política urbana brasileira como o Plano Diretor de Desenvolvimento Urbano e os planos, programas e projetos setoriais, esse elemento faz parte das áreas verdes e pode ser incluído nesses planos setoriais (NESPOLO, et al.).

Apenas seis estados brasileiros possuem legislação estadual ou incentivo para elaboração de Planos de Arborização e o estado do Rio de Janeiro não se encontra nessa lista, de forma que fica a cargo dos municípios elaborarem seus instrumentos de planejamento de arborização. $O$ instrumento urbanístico utilizado como segunda forma de análise quantitativa na pesquisa foi Plano Diretor Urbanístico de Duque de Caxias (2006). Ainda em vigor, o plano menciona arborização urbana em uma única vez. Em sua classificação viária, indica que tanto em ruas coletoras quanto em arteriais deverão existir árvores a cada 20 (vinte) metros, e que nas ruas locais essa distância caia para 10 (dez) metros.

\section{RESULTADOS}

Com a comparação das temperaturas de superfície (Figura 4) com o mapa de densidade populacional (Figura 5) foi possível conferir que nas regiões mais densamente ocupadas as temperaturas de superfície apresentaram temperaturas até 6 graus mais elevadas que nas regiões com um baixa densidade ou nas áreas de preservação. A região central dos mapas onde apresentam-se as maiores concentrações populacionais e maiores temperaturas de superfície corresponde ao eixo do Rio Roncador, onde ocorre um alto número de ocupações irregulares margeando os rio, percebe-se também nesse local a perda da vegetação nativa e alta taxa de impermeabilização do solo. Tal dado reforça a necessidade de atenção à expansão da mancha urbana nas regiões de aumento populacional em detrimento da cobertura vegetal.

Figura 4-Mapa temperatura de superfície Figura 5-Mapa de densidade populacional 

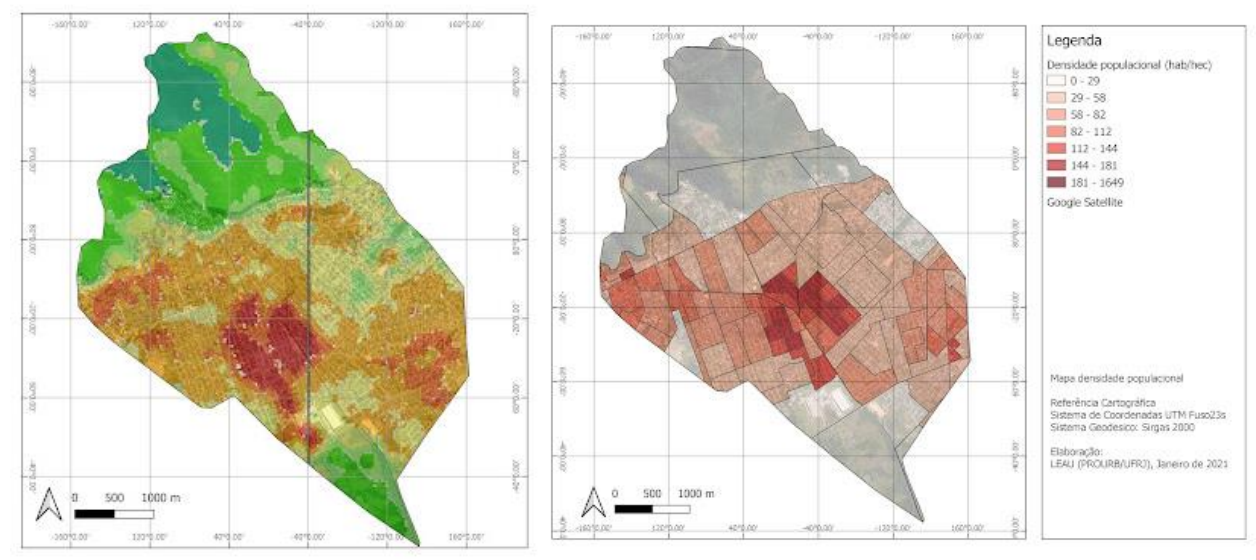

Fonte: Elaboração própria

$\mathrm{Na}$ área mapeada, foram encontradas 706 árvores em $177 \mathrm{~km}$ de ruas. Dessas, 172 estavam concentradas em uma única avenida, a Automóvel Clube, com $4 \mathrm{~km}$ de extensão. Nesse mapeamento, o índice ficou em 3,9 árvores por km. Desconsiderando a Av. Automóvel Clube, esse índice cai para 3,01 árvores por km. São 3 árvores a cada 1.000 (mil) metros, o índice de indivíduos arbóreos por quilômetro de rua indica que seriam necessárias 200 . Se fosse levado em conta o Plano Diretor de Duque de Caxias, precisar-se-ia de 100 árvores por quilômetro. Tendo como referência o índice de indivíduos arbóreos por quilômetro de rua percorrido dentro do bairro elaborado por Silva Filho et al (2000). a bacia carece de 34.694 novas árvores.

Quadro 1- Árvores por quilômetro de rua

\begin{tabular}{|l|c|c|c|c|}
\hline \multicolumn{1}{|c|}{ Referência } & $\begin{array}{c}\text { Quantida } \\
\text { de de } \\
\text { árvores } \\
\text { mapeada } \\
\text { s }\end{array}$ & I A/Km & $\begin{array}{c}\text { I A/Km } \\
\text { ideal }\end{array}$ & $\begin{array}{c}\text { I A/Km } \\
\text { pelo Plano } \\
\text { Diretor }\end{array}$ \\
\hline Ruas & 534 & 3,1 & 200 & 100 \\
\hline Av. Automóvel Clube & 172 & 43 & 200 & 50 \\
\hline Total & 706 & 3,9 & 200 & 100 \\
\hline
\end{tabular}

Fonte: Elaboração própria

O levantamento revelou que a área também possui condições de arborização muito aquém do que determina o próprio Plano Diretor. Tendo como parâmetro o plano municipal, ainda seriam necessárias cerca de 16.994 novas árvores. Considerando os dados socioeconômicos do território, onde predomina a população de baixa renda, suas condições urbanísticas, e os dados apresentados no presente estudo, os achados indicam um cenário onde as características de arborização das ruas reforçam um baixo índice de bem-estar urbano e qualidade da paisagem urbana da bacia.

\section{CONCLUSÃO}

A pesquisa buscou evidenciar a importância de um planejamento urbano no recorte de estudo que esteja alinhado com estudos das condições ambientais e planejamentos dos espaços livres. 


\section{Revista Científica ANAP Brasil}

ISSN 1984-3240 - Volume 14, número 35, 2021

Duque de Caxias hoje permanece, segundo o IDSC Brasil (Índice de Desenvolvimento Sustentável das Cidades), com uma avaliação baixa em relação à ODS sobre Cidades e Comunidades Sustentáveis, mostrando assim, sua falta de planejamento ecológico e sustentável. Como já citado por este estudo, Duque de Caxias enfrenta altas temperaturas em dias quentes, que poderiam ser atenuadas caso houvesse crescimento e planejamento de seu corpo arbóreo urbano. A arborização urbana é um grande fator colaborador aos ODS, sendo esta uma valiosa ferramenta para o alcance de cidades mais habitáveis e resilientes.

Todas as estratégias aqui colocadas foram expostas a fim que estas orientem uma adequada ocupação territorial - que possa reduzir os impactos causados pela expansão urbana. Com isso, recomenda-se um plano de arborização associado a estratégias para melhoria da qualidade de vida e controle sobre o crescimento urbano, buscando reduzir ao máximo os efeitos nocivos da urbanização.

A falta de diretrizes estaduais e federais em relação à arborização urbana é um desafio que as cidades brasileiras precisarão enfrentar em um futuro próximo, entendendo que esse tema vem se tornando central graças ao incentivo dos ODS da ONU e da crescente alta nas temperaturas decorrentes das mudanças climáticas. O planejamento das cidades precisa adotar medidas para enfrentar o problema, combatendo as ilhas de calor. A arborização urbana é um instrumento central nesse planejamento visando um espaço de vida mais saudável e mais confortável para sua população.

\section{AGRADECIMENTOS}

Agradecemos ao CNPq e à FAPERJ pelo apoio financeiro a partir da concessão de bolsas. Também agradecemos aos colegas que integram o Laboratório de Estudos de Águas Urbanas (PROURB/UFRJ) que contribuíram de diferentes formas para o desenvolvimento desta pesquisa.

\section{REFERÊNCIAS}

BIONDI, D. Curso de arborização urbana. Curitiba, UFPR, 2000

BITTAR, D.A. Quantificação e Qualificação da Arborização em áreas verdes urbanas na Bacia Hidrográfica do Ribeirão das Anhumas. Campinas/ São Paulo, 2018.

BRITTO, Ana Lúcia; QUINTSLR, S.; PEREIRA, M. Baixada Fluminense: dinâmicas fluviais e sociais na constituição de um território. Revista Brasileira de História, v. 39, n. 81, p. 47-70, 2019.

COSTA, H. Desenvolvimento Urbano Sustentável: uma contradição de termos. Estudos Urbanos e Regionais, n.2, novembro 1999, p.57-71.

HERZOG, C. P. Cidade para todos: (re) aprendendo a conviver com a natureza. 1. Ed. Mauad X: Inverde, Rio de Janeiro, 2013

Mascaró, L. e Mascaró, J. J. Ambiência urbana. Masquatro, Porto Alegre; 3ạ edição, 2009.

MELLO, C. V. N. Diagnóstico da arborização do bairro Frigorífico, Nilópolis (RJ), como contribuição para um futuro plano de arborização urbana no município. Rio de Janeiro, Universidade Federal do Rio de Janeiro. 2020

MILANO, Miguel ; DALCIN, Eduardo. Arborização de vias públicas. Rio de Janeiro: Light, 2000. 


\section{Revista Científica ANAP Brasil}

ISSN 1984-3240 - Volume 14, número 35, 2021

MUNEROLI, Clenara Citron; MASCARÓ, Juan José. Arborização Urbana: Uso de espécies arbóreas nativas na captura do carbono atmosférico. REVSBAU, Piracicaba, São Paulo, p.160-182, 2010.

NESPOLO, Cássia Conceição da Cruz; ABREU, Emanoele Lima; VICENTE, Caroline Pardi; PERES, Renata Bovo. Planos Diretores de Arborização Urbana: Necessidade de Incorporação de Legislação Brasileira. REVSBAU. Curitiba, PR. p.42$55,2020$.

NEVES, L. et al. Mudanças de Uso e Cobertura da Terra e Áreas Suscetíveis à Inundação - Estudo de Caso do Município de Duque de Caxias/RJ. Revista do Departamento de Geografia, v. 37, p. 30-43, 2019.

ONU.ONU prevê que cidades abriguem $70 \%$ da população mundial até 2050. 2019. Disponível em <https://news.un.org/pt/story/2019/02/1660701> Acesso em: 07/2021 